\title{
ON RELAPSING PYREXIA IN LYMPHADENOMA, WITH AN ACCOUNT OF A CASE
}

\author{
By ARTHUR J. HALL AND J. S. C. DOUGLAS
}

\section{Introduction.}

RELAPSING or periodic pyrexia occurring in cases of lymphadenomatous type bas received much attention since the publication of Pel's (12) and more particularly of Ebstein's (3) cases in the early eighties. Altogether a considerable number of such cases have been recorded. MacNalty (8), in 1911, was able to collect thirty-two. Since then others have appeared, but the total of such records to-day is probably under fifty. Of these not more than a dozen can compare in duration with that of Ebstein; but, whether extending over shorter or longer periods, they all present certain features in common, and differ so markedly from what is seen in most other febrile diseases in temperate climates that their more close investigation seems desirable. due to:

In trying to compare them with each other certain difficulties arise,

(a) The great length of the ordinary charts, and the consequent difficulty of seaing the whole in a continuous line.

(b) The different thermometric scales used by British and continental observers.

(c) The varying ratio of width to height in the rulings of various types of charts.

(d) The different frequency of daily readings in different cases (four-hourly, eight-hourly, twelve-hourly).

To get over these difficulties and obtain comparable charts we have adopted a uniform standard chart, as follows : ${ }^{1}$

1. The paper is ordinary sectional scale-paper, ruled in inches and divided into tenths.

2. The Fahrenheit scale is adopted throughout.

3. All records are 'morning and evening only'. (Most of the recorded cases

1 The following statem ents of actual measurements refer to the original drawings from which the charts have been reproduced. It has not been found practicable to put the smaller sectional lines in the charts. Although individual charts vary in the size of their reproduction, they are all to the same scale, and made from drawings prepared as stated in the text. 
are already of this kind. In those few cases where the records are at more frequent intervals, care has been taken to take those a.m. and p.m. records which indicate most closely the general excursions of the temperature during each period, so that the chart may follow the original as closely as possible. For our present purpose we are concerned with variations of days, or even weeks, rather than of hours.)

4. Each degree Fahrenheit occupies one inch vertically. Each day occupies one-fifth of an inch horizontally-i. e. one-tenth for the morning, and one-tenth for the evening record. The charts, as compared with the ordinary temperature charts, are thus compressed laterally and expanded vertically.

5. At the end of each calendar month, a vertical line is drawn, so that, although each date is not recorded, yet the temperature of any particular morning or evening in any month can be ascertained by simple measurement, in inches and tenths.

6. In order to obviate any visual deceptions produced by lines joining one another at varying angles according to their distance apart, all temperaturelevels are shown by horizontal lines and all changes of level are joined by vertical lines. This arrangement, being so different from the 'dot and sloping line' with which we are familiar, gives the charts, at first sight, a strange appearance.

7. All horizontal space means actual length of time. One horizontal inch is five days, one month is six inches, more or less, according to the month. If there is a blank space, it means that for exactly so many days no record was made.

8. The standard charts here reproduced are accurate transcriptions of the originals (or carefully reduced to twelve-hourly records in cases where parts or the whole were four-hourly).

It is proposed in this paper to limit our remarks strictly to this question of the temperature peculiarity.

Most writers who have had the fortune to see one of these long cases, and the energy to record it, have taken the opportunity to give a short account of some or all of the previously recorded cases. Others have gone farther and published exceedingly valuable articles or even monographs on the subject. Amongst the latter the papers by F. Taylor (16), MacNalty (8), Batty Shaw (15), and Parkes Weber (18) contain much valuable information, with tabulated details and many original and interesting suggestions. These have been drawn freely upon in this paper, and we desire to acknowledge their help most fully. Particularly so in the case of MacNalty's thesis (8), published in 1911, which deals with the subject in a most thorough and masterly manner.

In considering these charts it is important to remember that they are not the product of one man's experience or one decade's work-they range in time over a period of over thirty years. Nor are they restricted to one area or to one country, or even to one continent. At rare intervals, in widely separated places, a case of this kind is recorded: sometimes it has been described as tuberculosis, at other times as lymphosarcoma, usually as lymphadenoma. Whatever may be the 
true pathology the one common factor which has called attention to them is the relapsing pyrexia. This diversity of recorders both in time and place makes the similarity of the pyrexia in all cases the more convincing.

\section{Account of a Case.}

A case of this kind has recently come under our observation. The circumstances were such as to make the diagnosis during life very difficult. The history is as follows:

On May 10, 1920, a woman eighteen years of age was transferred from the Surgical to the Medical side of the Sheffield Royal Hospital. She had been sent in a few weeks previously on account of a supposed tubercular kidney. No evidence of this was found, but during the week preceding her transfer the temperature had risen steadily.

On admission she was obviously very ill. There was severe headache, delirium at times, a dry coated tongue, high fever, and slight tenderness over the abdomen. Except for a few rhonchi there were no abnormal physical signs in the chest. The liver and spleen were not enlarged. There was a well-marked Kernig's sign on both sides. Nothing definite was known at that time as to her previous history except that she was said to have been in a sanatorium for tuberculosis.

On May 20 her condition renained much the same. Lumbar puncture was performed. The fluid was clear, and under considerably increased pressure anti-meningococcie serum was given intrathecally and again on the 23rd. About this date the temperature began to come steadily down, remaining subnormal from the 27 th. Her general condition improved greatly and she seemed to have made a remarkable recovery.

On June 2 she called attention to a small superficial skin abscess in the left axilla, which was opened and drained freely. She stated that she had been troubled with these previously, and the remains of others were seen in both axillae.

On June 14 she was sent up to the hospital's convalescent home in the country, where she continued to improve during the next week. Whilst she was still in hospital we heard that during her stay in a tuberculosis sanatorium she had suffered from previous attacks of pyrexia, but no details were known.

On June 21 she was sent back to hospital from the Annexe, her temperature having again gone up, with symptoms very similar to those in her previous attack. This fever was at first of hectic type, with extreme oscillations in the twenty-four hours. As it began to come down she got steadily worse. The spleen, which had not been palpable before, was enlarged and tender on June 24 . Stupor and delirium with incontinence and rapid wasting followed, and she died, jaundiced, on July 13.

On June 23, two days after her return from the convalescent home, she complained of much pain in the left axilla and another large boil had to be opened. It discharged very freely for some days.

An autopsy was made on July 14, of which the following is the report:

The post-mortem examination was made the day after death.

Petechiae were present in skin of hypochondriac region, about left breast, and beneath left clavicle. Two deep punched out ulcers and many smaller ones over right gluteal region.

Sinuses, with overhanging thin margins, opening into larger cavities beneath the skin were present in the left axilla. These were not discharging. In right axilla was a small punctiform opening leading to an abscess which was burrowing beneath the skin.

General jaundice was noted in the skin. 
On opening the skull, jaundice of the membranes was found, together with petechial haemorrhages on the inner aspect of the dura mater, whilst the piaarachnoid showed a little oedema, particularly posteriorly. No meningitis was found.

The brain was normal save for pallor due to anaemia.

\section{Lymphatic System.}

No enlargement of glands was found save for a slight swelling of those at the bifurcation of the trachea, and in the post-thoracic region, which presented some carbon pigmentation. Lumbar glands slightly swollen.

An enlarged caseous gland and, near to it, a calcareous nodule were found in the mesentery.

A slightly enlarged gland was found in the left axilla, pink in colour, and suggestive of reaction to septic absorption. An enlarged pigmented gland was seen at root of right lung.

Spleen. Weighed $11 \mathrm{oz}$, being enlarged and congested. Small infarcts were present, and on section the organ showed much congestion and multiple abscesses, but no lymphadenomatous deposits were visible to the naked eye.

\section{Respiratory Tract.}

Larynx and Trachea. Nil.

Pleural Cavities. A little bile-stained fluid present on both sides. No adhesions found.

Right Lung. The colour was generally pale, but a little anthracosis was present. Two abscesses were found on the posterior aspect of the lower lobe about its middle, and another in the lower fringe of the middle lobe. Scattered purulent bronchitis was noted. The lung weighed 9 ozs.

Left Lung. A scar was present at the apex which was found microscopically to be due to tubercle. Several abscesses were present in the upper lobe where in contact posteriorly with the lower lobe. On section, oedema and traces of bronchitis were noted.

\section{Circulatory System.}

Pericardium. Normal save for: some excess of fluid which was bile-stained.

Heart. Anterior aspect of right ventricle exhibited petechial haemorrhages. The heart-muscle was normal save for anaemia. Endocardium healthy, save that the valve cusps showed traces of bile-staining. The organ weighed $7 \mathrm{oz}$.

Vessels. No pathological change observed.

Tongue. Normal.

\section{Alimentary System.}

Pharynx. Normal.

Oesophagus. Normal.

Peritoneum. Presented slight oedema and scattered petechiae in right lumbar region of posterior abdominal wall.

Stomach. Distended with gas.

Intestines. Scattered petechiae on serous and mucous surfaces of small and large bowel. Bile-staining was noted.

Liver. Weighed $4 \mathrm{lb} .9 \mathrm{oz}$, being much enlarged. The surface was mottled, 
being pale in places and in others reddish brown, and showed petechiae. On section the tissue was soft and bile-stained, and showed, mingled with the brownishyellow colour of the liver substance, whitish spots and Jines of a semi-opaque appearance.

Pancreas. Pale but normal.

\section{Urinary Tract.}

Right Kidney. Enlarged, weighing 6 oz. Anaemic. The capsule was adherent. On section the surface was pale and smooth, but cortex and medulla were well differentiated.

Left Kidney. Also enlarged, weighing 7 oz., presenting the same appearance as the right.

Ureters and Bladder. Normal.

Supra-renal Glands: Healthy.

Uterus and Appendages. Normal.

Breasts. Normal.

Bone Marrow. Red in colour.

\section{Microscopical Examination.}

The appearance of the organs, as above described, did not allow of a definite diagnosis, that of the spleen being compatible with a septic condition, especially as septic foci were found elsewhere in the body, whilst the semi-opaque material which permeated the liver suggested new tissue formation which, apart from other considerations, was consistent with infiltration by diffuse new growth, hypertrophic cirrhosis in an early stage, lenkaemia, or lymphadenoma. Leukaemia was, of course, excluded by the absence of blood changes during life, and lymphadenoma, which had been expected, seemed doubtful in the absence of corresponding naked-eye glandular or splenic changes. The liver on section contained areas of tissue proliferation of lymphadenomatous type in which were embedded large cells, some of which were mono-, others bi-, and others again multi-nucleated, resembling the giant-cells found in that condition.

The presence of abscesses in the lung and spleen was confirmed microscopically, whilst pyogenic staphylococci were isolated from the pus in the axilla and from the spleen.

Lymphadenomatous tissue of type similar to that found in the liver was found scattered in small nodules throughout the spleen. Similar changes were seen in one of the mediastinal glands.

The kidney showed the presence of a little chronic nephritis. A few glomeruli were fibrosed, whilst there was a cellular increase in the intertubular connective tissue. Some of the tubules contained débris, and cloudy swelling was evident in the convoluted tubules.

Although at first the giant-cells were thought possibly to have a parasitic origin, yet no evidence in support of this idea could be found, and therefore pathologically the case seemed to be an example of the 'cryptic' type of lymphadenoma with the bulk of the change affecting liver and spleen, though lymph glands had not altogether escaped; the sepsis being the terminal phenomenon which accelerated death.

During the short terminal period of her illness in hospital no definite diagnosis was made. Even at autopsy the naked-eye conditions were somewhat indefinite, and it was not until a microscopic examination had been made that the diagnosis became tolerably certain. Some months later, thanks to the courtesy 
of Dr. Rennie, Tuberculosis Officer to the City, we were shown the record of the patient's stay in the City Tuberculosis Sanatorium during the six months preceding her admission to hospital. This confirmed the pathological findings and showed that we had been dealing with a typical example of relapsing pyrexia in Hodgkin's disease (Fig. 7). The following are a few notes from Dr. Rennie's record :

'She began with what was called influenza in November 1918 (during the epidemic), and was laid up in bed for two weeks. Since then she has been unable to work regularly and has never menstruated.

"In September 1919 she attended at the tuberculosis dispensary, where she was classified as a case of "suspected tuberculosis". Sputa negative.

"In December 1919 she had her first recognized attack of pyrexia as shown in the chart.

'During five months' residence in the sanatorium she had five such attacks. Eventually, owing to the continued absence of pulmonary or other signs, and the recurrence of lumbar pain, renal tuberculosis was suspected and she was sent into hospital, as stated above.'

\section{Periodicity.}

It is obvious, in looking at the charts of Ebstein's (Fig. 4) and Melland's (Fig. 2) cases, that the waves of pyrexia succeed each other with remarkable regularity. But it is also evident that the intervals from one wave to its successor differ considerably in the two. In the former there are eight pyrexial peaks during seven calendar months, whilst in the latter there are twelve during a similar period. If these two hundred and ten days (seven months roughly) are divided equally, it would give a recurrence about every twenty-six days in the former, and every seventeen days in the latter. If one measures on the charts from the middle of each pyrexial wave to the middle of its successor, it will be found that on the whole this interval or 'span' in each case is repeated with considerable constancy. Each recurring wave is surprisingly punctual.

This method of measuring the curves and referring to them in terms of 'span' seems more useful than to refer to 'pyrexial and apyrexial periods' of so many days each. How misleading this latter method may be is well seen in Ebstein's (Fig. 4) and in Melland's case (Fig. 2). In the former, if by an 'apyrexial period' one means the number of days during which the temperature is normal or below normal, the duration of 'apyrexial periods' from December to March would be a steadily increasing one, whereas in reality the waves during that time are extraordinarily regular. Similar variability in the length of actual apyrexial, and, consequently, of pyrexial periods, is seen in Melland's case, and e]sewhere in the charts.

The fact is that the waves may be perfectly regular in periodicity but at a slightly different level, the temperature dipping more or less in the different waves, so that the exact date at which it crosses the normal line of 98.4 is not so 
jmportant from a measuring point of view as the distance between the two successive waves. If the charts of the twonty-one cases recorded in the figures are measured according to 'pyrexial span' in this way, that is from the middle of one wave to the middle of the next, it is found that they vary considerably in different cases, from five or six days in MacNalty's Case II (Fig. 21), up to thirty-six days in his Case I (Fig. 26). But with the exception of these two cases and the long record of Hammer's (Fig. 1), which also has a very short span-the remaining 19 charts here reproduced have a 'span' between about fourteen and twentyfive days.

Thus in round numbers:

The span is less than ten days in 9 per cent.

between fifteen and twenty-five days in 86.5 per cent.

greater than ", " $\quad$ in. 4.5 per cent.

Another feature of interest which is shown by this measurement is that in each individual case the span remains constant within the limits of comparatively few days. There are exceptions (particularly in Hammer's case and in the one recorded in this paper) which will be referred to later. Another exception must be made in those cases where the chart is continued up to the time of death. This event is frequently preceded by a change in rhythm, which is so similar in different cases as to form an almost characteristic pre-lethal period (vide Ebstein (Fig. 4), Weber (Fig. 5), Pel I (Fig. 8) and III (Fig. 25), Whittington (Fig. 11), MacNalty IV (Fig. 15), Völckers (Fig. 10)).

These pre-lethal irregularities have been omitted from the following table on account of the difficulty in measuring them.

Table of Successive Pyrexial Spans (in Days).

\begin{tabular}{|c|c|c|c|c|c|c|c|c|c|c|c|c|}
\hline & & & & & & & & & & & & \\
\hline MacNalty II & 7 & 5 & 5 & 6 & 7 & 7 & $5 \frac{1}{2}$ & 7 & & & & \\
\hline Hammer & 12 & $\begin{array}{l}9 \\
7\end{array}$ & 9 & 9 & $\begin{array}{l}6 \\
81\end{array}$ & ${ }_{81}^{8}$ & 8 & $\begin{array}{r}8 \\
14\end{array}$ & 9 & $\begin{array}{l}8 \\
7\end{array}$ & 8 & $\begin{array}{l}6 \\
71\end{array}$ \\
\hline & & $7 \frac{1}{2}$ & 11 & $\begin{array}{l}0 \\
9 \frac{1}{2}\end{array}$ & $9^{2}$ & & & & & & & \\
\hline Weber & 13 & $13^{2}$ & 15 & $16^{2}$ & 14 & 17 & & & & & & \\
\hline MacNalty III & (?) 20 & 14 & 14 & & & & & & & & & \\
\hline${ }^{*}$ Renvers & 13 & 13 & 14 & (?) 21 & (?) 17 & (?) 16 & & & & & & \\
\hline Taylor, F. II & 22 & 20 & 17 & 12 & - & - & 14 & 14 & 16 & 17 & & \\
\hline Pel II & 18 & 16 & 16 & 18 & & & & & & & & \\
\hline Shaw, B. & 18 & & & & & & & & & & & \\
\hline Melland & 20 & 17 & 17 & 16 & 18 & 17 & 18 & 18 & 21 & 20 & 16 & \\
\hline Völckers & 20 & 20 & 20 & 20 & 20 & & & & & & & \\
\hline Hall, de Havilland & 20 & 20 & 20 & 20 & & & & & & & & \\
\hline *Musser I & 20 & 20 & 20 & & & & & & & & & \\
\hline${ }^{*}$ Musser II & 21 & 16 & 22 & 15 & & & & & & & & \\
\hline *Holbauer & 21 & 22 & & & & & & & & & & \\
\hline Whittington & 22 & 22 & & & & & & & & & & \\
\hline Hauser & 24 & 19 & 19 & 21 & 23 & 20 & & & & & & \\
\hline MacNalty IV & 19 & 21 & 23 & 22 & & & & & & & & \\
\hline MacNalty V & 23 & 27 & 18 & 18 & 23 & 23 & & & & & & \\
\hline Ebstein & 2 & 22 & 24 & 24 & 25 & 24 & 26 & 22 & & & & \\
\hline MacNalty I & 3 & 36 & & & & & & & & & & \\
\hline Hall and Douglas & 1 & 39 & 37 & 17 & 23 & & & & & & & \\
\hline
\end{tabular}


From this table it is seen that in most cases the periodicity does not vary in any one case by more than five days, even during many months, as in Ebstein's and Melland's cases.

In some, such as Völckers', de Havilland Hall's, and Musser I, the punctuality of recurrence is remarkable. This punctuality is further emphasized by the following incident.

In MacNalty's Case I only two successive waves are recorded on the chart published in his paper. These, however, show great similarity to each other, and as the span was much longer than that of any other record seen, the place on the chart where a third pyrexial wave should have come was measured and marked out on the standardized chart (Fig. 26).

Some days later when reading his account of the case the following passage was found: "On leaving the hospital, the patient went to his own home at Ramsgate, when, for a space of three weeks, he appeared to recuperate rapidly: he then had a pyrexial attack which lasted from twelve to fifteen days, the temperature rising several times to $103^{\circ}$.' On looking at the marks previously made on the chart, it was found that the apyrexial period, as calculated by measurement, was exactly $4 \frac{1}{5}$ inches (twenty-one days), and the estimated pyrexial period had proved accurate in every detail.

The two cases in which the variation in periodicity is very considerable are Hammer's (Fig. 1) and the case recorded in this paper (Fig. 7). In the former (Hammer's case), whilst most of the 'spans' range between seven and nine days, there is one of fourteen days intervening in a group of $8 \frac{1}{2}$ to 7 , i. e. just about double the length. It seems possible that this may be explained by one 'cycle' having for some reason been missed out at this point.

A similar explanation seems possible in the gross irregularities of our case. There are two long spans of thirty-nine and thirty-seven days, whilst the two following, if added together, form a span of forty, which is very nearly the same as the two previous long ones.

In four of the cases, Hofbauer's (Fig. 20), Renvers'(Fig. 18), and two of Musser's (Figs. 17 and 19), we have drawn what may be called 'conventional' charts. These authors do not publish the actual temperature charts in their papers, but merely state the dates at which the pyrexial periods began and ended, and this is recorded in the standard charts by the straight lines above and below the normal. They therefore merely record time and not height of temperature.

Some of these show marked regularity of 'span', but owing to the alsence of a definite record it is difficult to measure them as accurately as the rest. In the case of Musser I (Fig. 17) the full record ends in January. After that the patient was only seen at rare intervals, and it is stated that on certain definite dates in the remaining months the temperature was raised or subnormal. These dates are indicated by solid lines, and it is found they correspond with what would have been the case had the recurrences been regular, as shown by the dotted line.

In addition to regularity in length of span there is on the whole a striking 
similarity in the duration of successive periods of pyrexia, and in the height to which they attain. In other words, the 'form' of the wave in each individual case is fairly constant. The variation in height rarely exceeds two degrees, and is usually not more than one or one and a half. Thus, in Ebstein's Jong chart the peaks vary from $104.8^{\circ}$ to $106.8^{\circ} \mathrm{F}$. In Melland's they vary from $102^{\circ}$ to $103^{\circ} \mathrm{F}$. MacNalty's Case V (Fig. 16) shows the greatest irregularity in this respect.

These charts also show clearly the gradual stepping upwards and downwards of the pyrexial waves. As was noted by MacNalty, this steppage often precedes the point at which the temperature rises above the normal level, and is quite well seen whilst the temperature is still subnormal. It is seen in so many of the records that it is unnecessary to point out particularly good examples.

Lastly, the very low temperature records in the apyrexial periods are a feature of many of the charts.

The pyrexial records which correspond most nearly to these of lymphadenoma are found in that group of diseases which in most cases are known to be due to living organisms of various kinds-malaria, relapsing fever, rat-bite fever, trench fever, \&e.

If we compare the 'span' in these various infections it is found that, as in the cases of lymphadenoma, they vary from each other considerably ; thus malarial fever has the shortest span, two or three days; rat-bite fever, five days; trench fever, six or seven days; relapsing fever, fourteen days.

In lymphadenoma it has been shown that as a rule the 'span' is longer than the longest of these known organismal fevers. On the other hand, in two of the recorded cases (MacNalty II and Hammer) the span is as short as that of trench fever or relapsing fever, and nearly as short as that of rat-bite fever. Figs. 21, 22, and 23 show the standardized charts of MacNalty's Case II, of trench fever and of rat-bite fever cases respectively. The similarity of the charts in the three diseases is considerable. At least four of the lymphadenoma cases (Weber, MacNalty III, Renvers, and Taylor II) have spans no longer than those of relapsing fever. This difference in length of span does not therefore seem to be an insuperable argument against the view of its organismal origin; for, as was said above, there are considerable differences in span amongst those diseases known to be due to organisms.

Well-marked 'steppage' lasting over several days, such as is found in the slow long pyrexial waves of lymphadenoma, is obviously impossible in the more frequent and short waves of the fevers now under consideration. Even in these, however, it is frequently present to some extent (vide Fig. 24).

The very low subnormal temperature characteristic of the apyrexial periods of lymphadenoma is, however, quite eclipsed by those seen in relapsing fever. Rabagliati (13) records cases in which it reached depths $\left(92.5^{\circ} \mathrm{F}\right.$.) lower than one would have thought compatible with life. As regards punctuality of recurrence referred to above, it is hardly necessary to emphasize how absolute this punctuality may be in the other periodic fevers, such as malaria, relapsing fever, \&c. Finally, the remarkable feeling of well-being which is so frequently described in these 
long cases of lymphadenoma has its counterpart in some of the other periodic fevers.

Thus in 'rolapsing fever' reference is made to the difficulty of persuading patients to stay in hospital during the apyrexial period, because they feel quite well. In the article on relapsing or famine fever in Allbutt and Rolleston, Rabagliati (13) writes: "Although I might succeed in keeping my patients in bed for a few days, yet they generally got up towards the close of the interval and before the relapse, which often therefore came upon them with all the force of the onset of a new disease.'

In the case which we record above, although it proved fatal a few weeks later, the girl seemed so well that she was able to go to a convalescent home and get about, even after a series of pyrexial attacks recurring at intervals during six months. This is possibly one of the reasons why more of these long charts cannot be obtained. The patients decline to stay in hospital during the long apyrexial periods.

It seems therefore that on the grounds of the pyrexia alone there is considerable evidence to suggest that this relapsing pyrexia may be due to some organismal infection, and the result of its life cycle.

It is obvious, however, that there are many difficulties in accepting this view. In many cases of lymphadenoma no such recurrent pyrexia is observed, but it is possible that in a less marked form it may be present at some period of the disease more frequently than is commonly thought. MacNalty alludes to this, and in looking over old records of these cases it is surprising to find how many of them show a definite tendency to recurrent pyrexia. Still; it is quite certain, as was pointed out by Gowers (21), that this recurrent pyrexia may be absent for long periods of the disease, or that it may be replaced by irregular pyrexia showing no periodicity. On the other hand, the periodic recurring pyrexia may continue through the whole course of the disease (Whittington's case, Fig. 11). Most commonly its advent means the beginning of the end, although that may not be for many months.

$\mathrm{Up}$ to the present no definite organism is generally recognized as the cause of lymphadenoma in any of its forms, but if the conclusions arrived at from a consideration of the pyrexia alone are sound, such an organism may yet be found, perhaps of protozoal type, and it is possible that, as in other cases of recurring fever, such causal organism may be detectable only at certain stages of the pyrexial cycle. In some of the cases careful investigations have been made, but it must be remembered that many of these cases were recorded at a time when much of the present-day knowledge of what have been termed 'protistal' diseases did not exist, and that investigation on such lines were lacking.

Cases of this type are not common, but further exbaustive investigations of the blood, or, if possible, of the juice from a lymphatic gland at a suitable period of the pyrexial cycle in such cases, seem desirable, and hold out the hope of a fruitful result. 


\section{Conclusions.}

1. In certain cases of lymphadenoma there is a type of relapsing pyrexia which differs in certain respects from that seen in any other disease.

2. It resembles the pyrexia seen in that group of recurring fevers which includes malaria, relapsing fever, rat-bite fever, and some others, in :

(a) Regular periodicity;

(b) Gradual ascent by steppage and sometimes similar gradual descent;

(c) Very low temperatures with apparently complete recovery in the apyrexial periods.

3. It differs from them in the greater length of span, which is usually from fifteen to twenty-five days, but may extend even to thirty-six days. It is usually fairly constant for each individual case.

\section{REFERENCES.}

1. Burton-Fanning, F. W., Brit. Med. Journ., Lond., 1921, i. 886.

2. Byam, W., 'Trench Fever', chart 4, Oxf. Med. Publications, 1919.

3. Ebstein, W., Berl. klin. Woch., 1887, xxiv. 565 and 837.

4. Hall, de Havilland, Practitioner, Lond., 1911, 1xxxvi. 473.

5. Hammer, Virchow's Archiv f. Path. Anat. u. Physinl., Berlin, 1894, cxxxvii. 280.

6. Hanser, A., Berl. klin. Wach., 1889, xxvi. 692.

7. Hofbauer, Zeitschr. f. Heilkunde, 1898, xix. 21.

8. MacNalty, A. S., Quart. Journ. Med., Oxford, 1911-12, v. 58.

9. Melland, C. H., Edin. Med. Jour'n., 1911, New Ser., vi. 156.

10. Musser, J. H., Trans. Assoc. Amer. Phys., Phila., xvi. 638.

11. Ofenheim, E. von, Proc. Roy. Soc. of Med., Lond., 1908-9, ii. (Clin. Sect. 165).

12. Pel, P. K., Berl. klin. Woch., 1885, xxii. 3, and 1887, xxiv. 644 . i. 1167 .

13. Rabagliati, A., 'Relapsing Fever', Allbutt and Rolleston's System of Med., Lond., 1905,

14. Renvers, Deutsch. med. Woch., Leipz., 1888, xiv. 753.

15. Shaw, H. Batty, Edin. Med. Journ., 1901, New Ser., x. 501.

16. Taylor, F., Guy's Hosp. Rept., Lond., 1906, lx. 1.

17. Völckers, G., Berl. klin. Woch., 1889, xxvi. 796.

18. Weber, F. Parkes, Proc. Roy. Soc. of Med., Lond,, 1917, x. 8.

19. Whittington, T. H., Quart. Journ. Med., Oxford, 1915-16, ix. 83.

20. Willeox, W. H., Proc. Roy. Soc. of Med., Lond., 1920, xiii (Sect. of Med. 77).

21. Gowers, W. R., Reynold's J. R. System of Med., Lond., 1879, v. 306. 

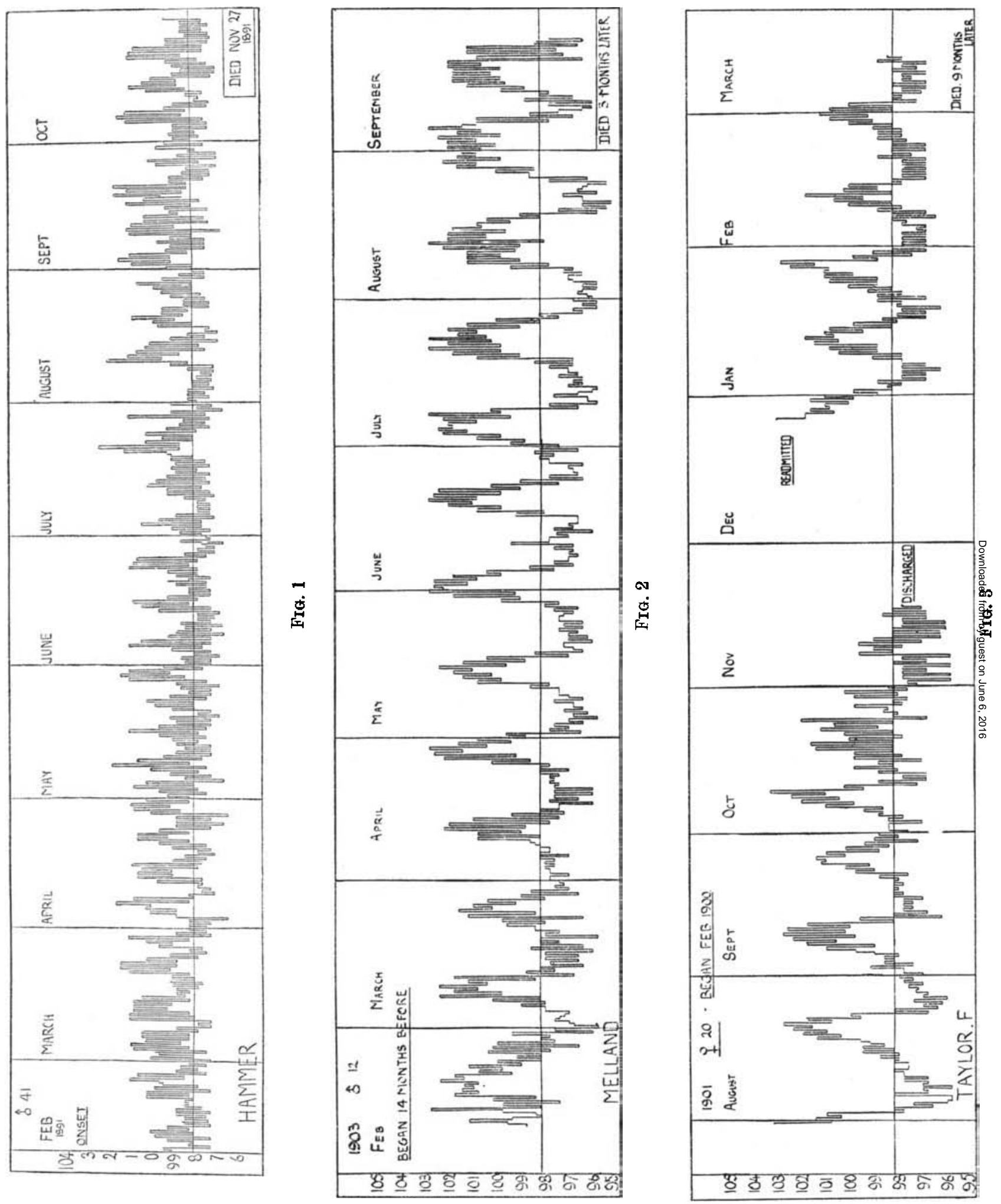

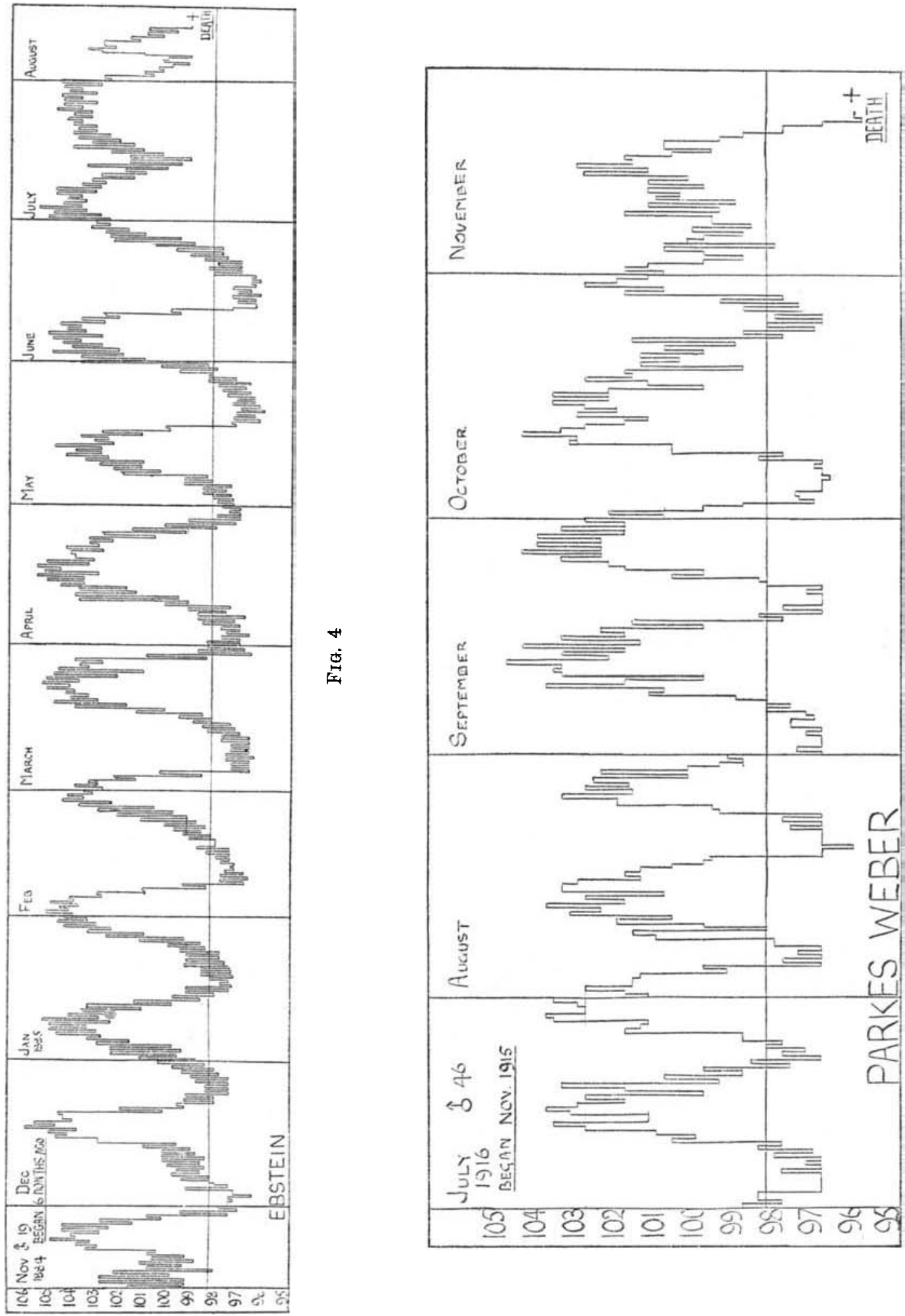

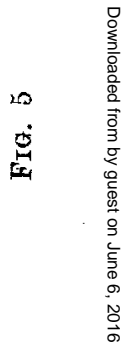



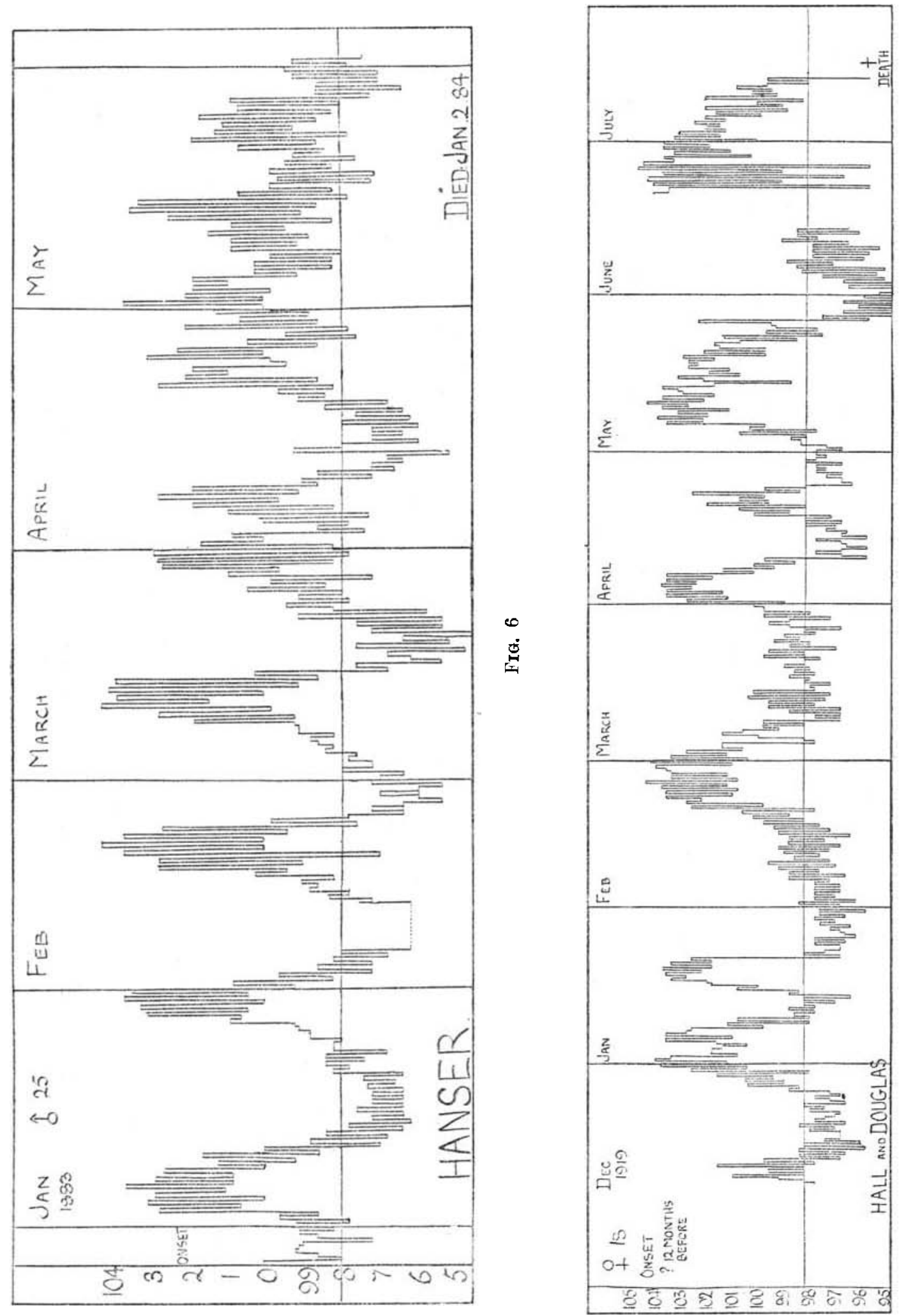

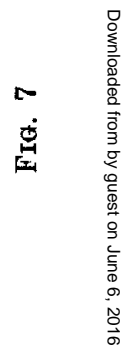




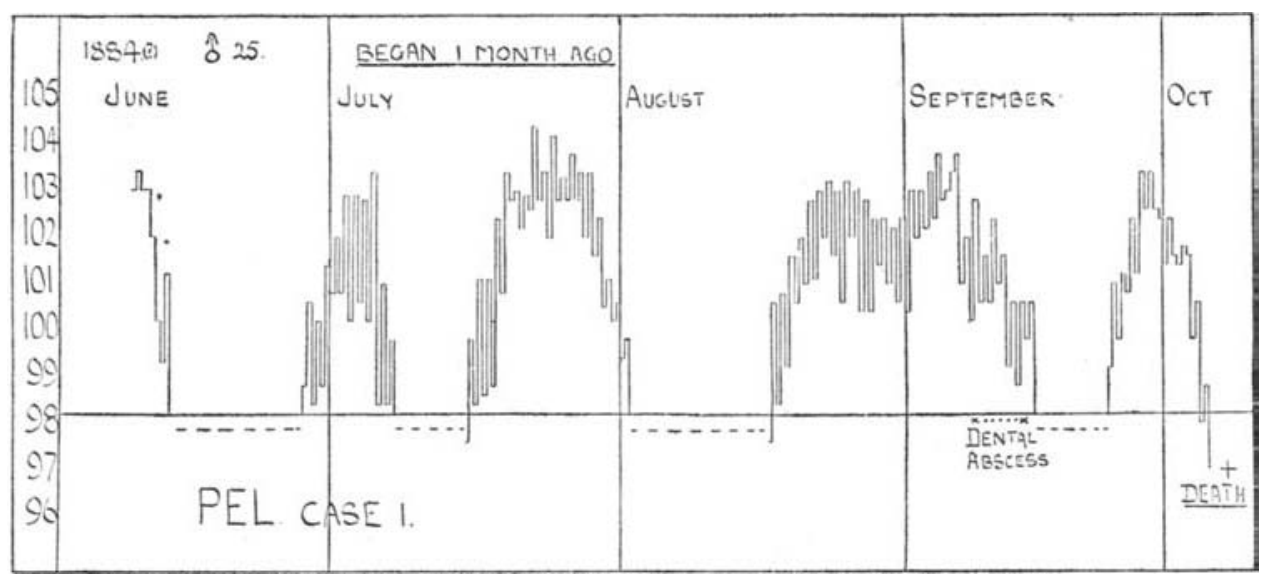

FIG. 8

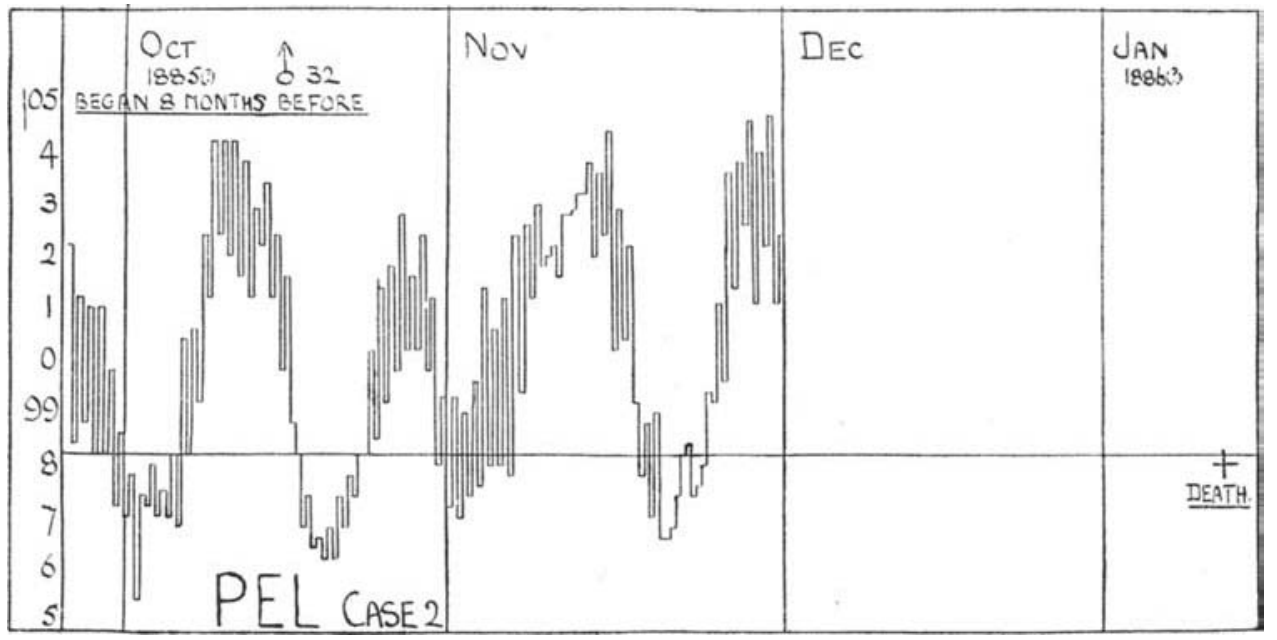

FIG. 9

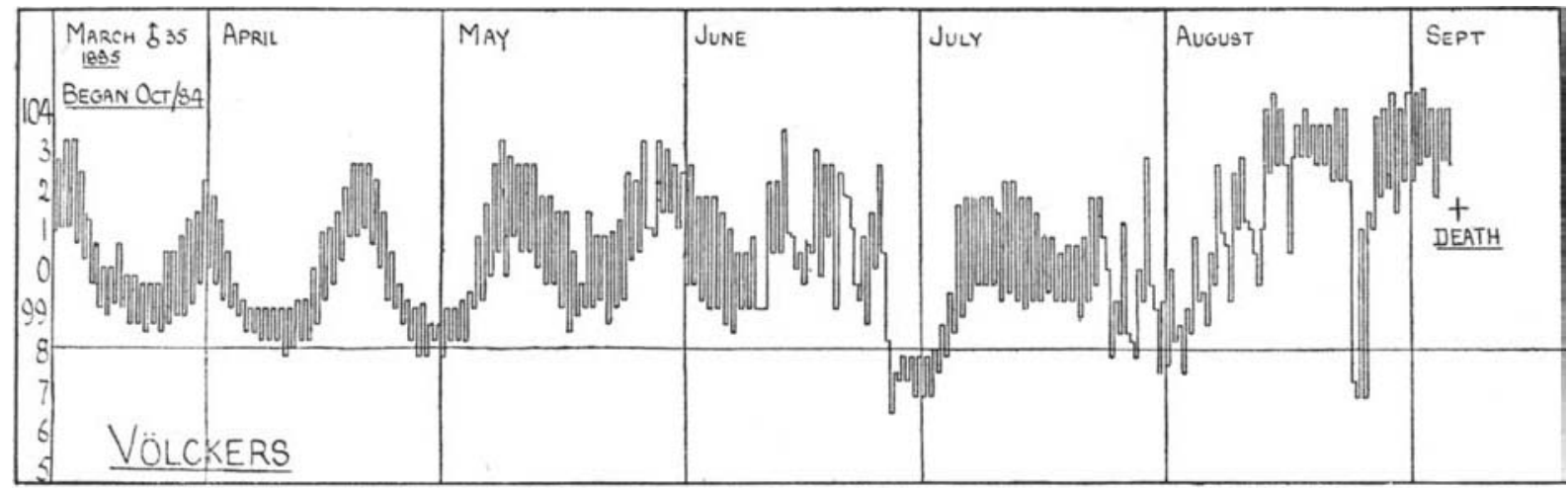

Fig. 10

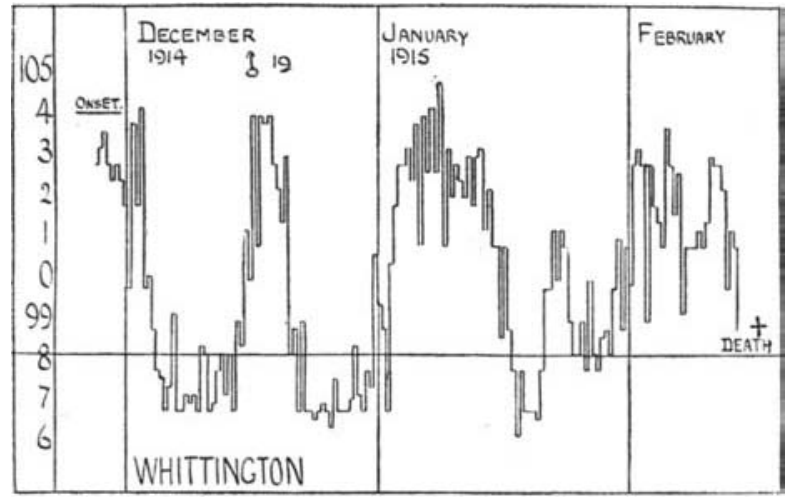


FIr. 12

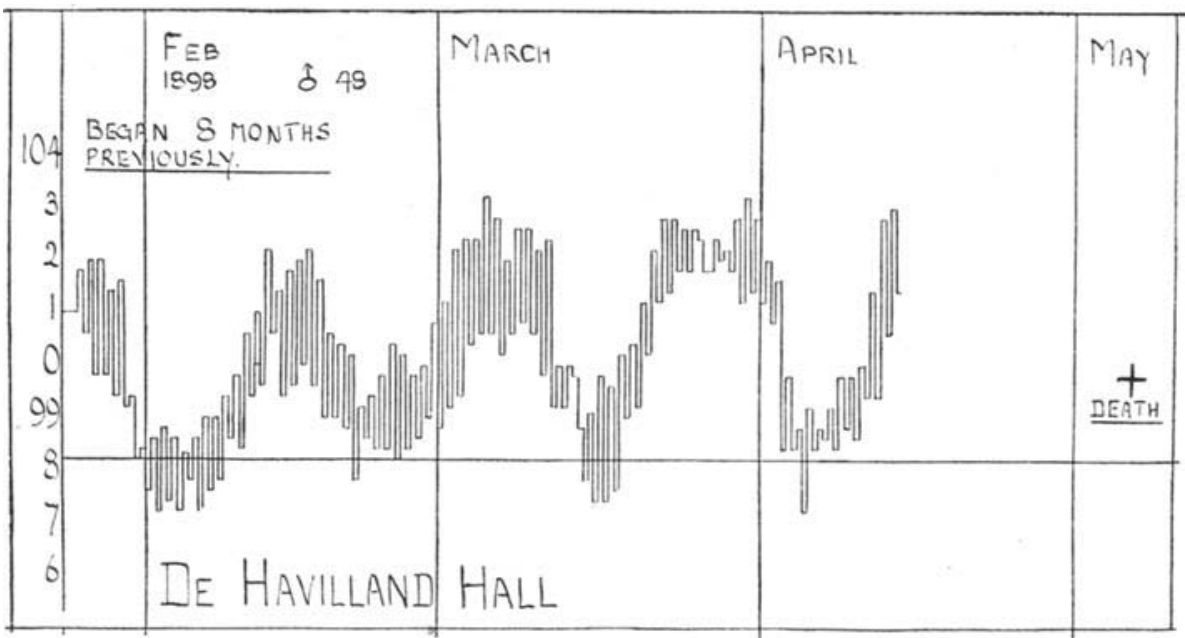

FIG, 13
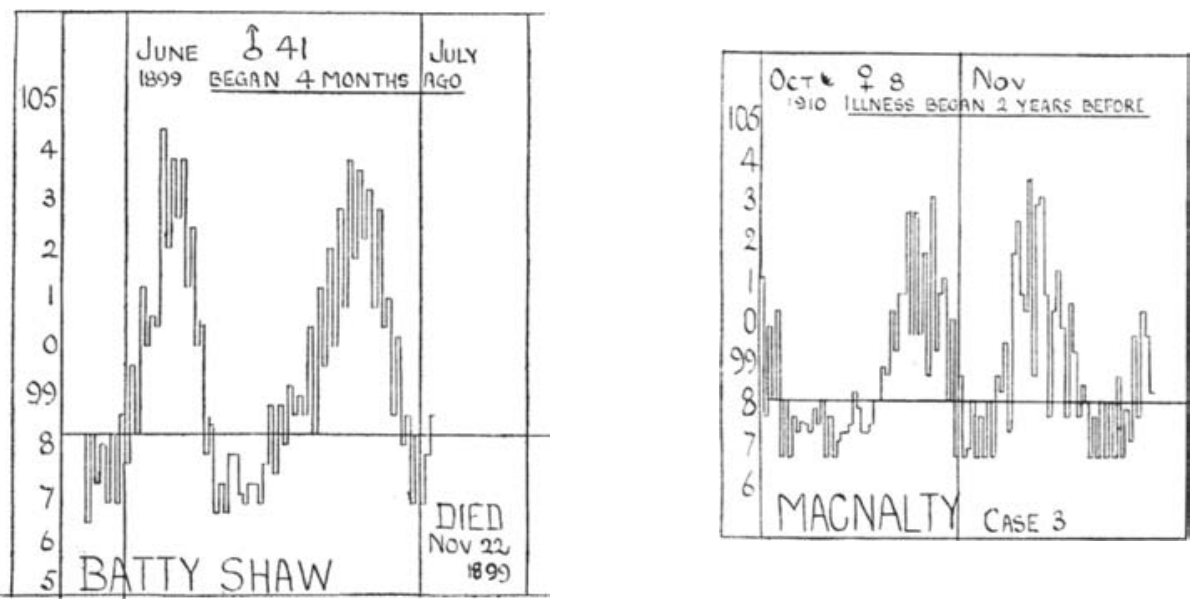

Fia. 14
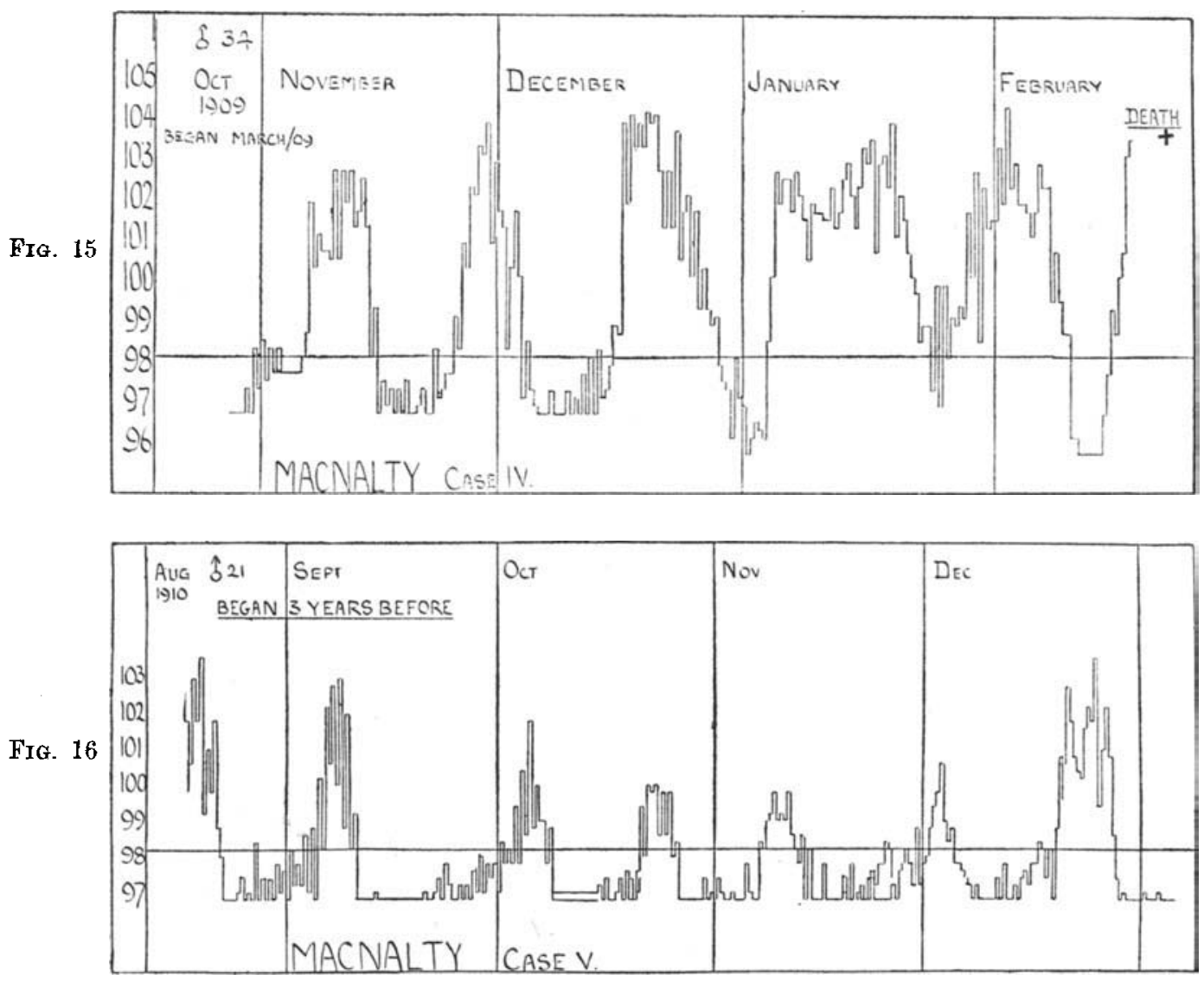


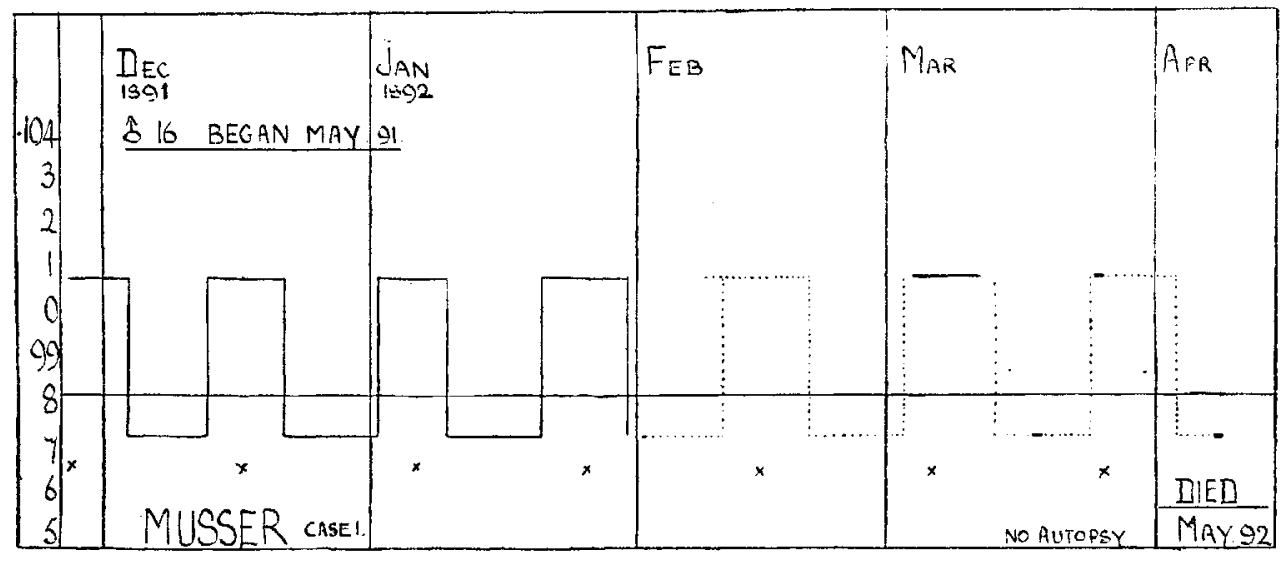

Fıg. 17

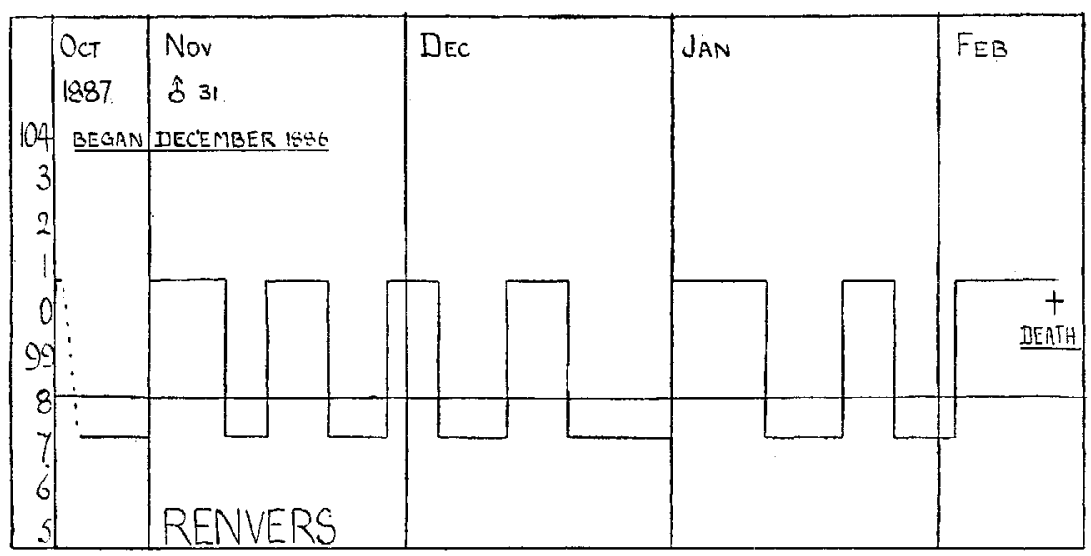

FIG. 18

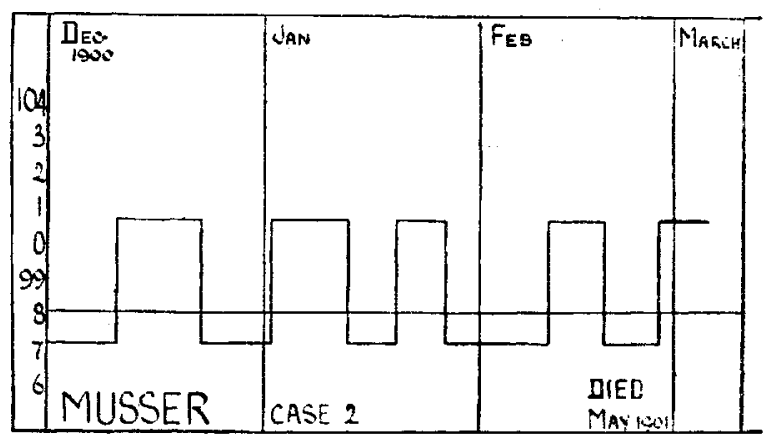

FIG. 19

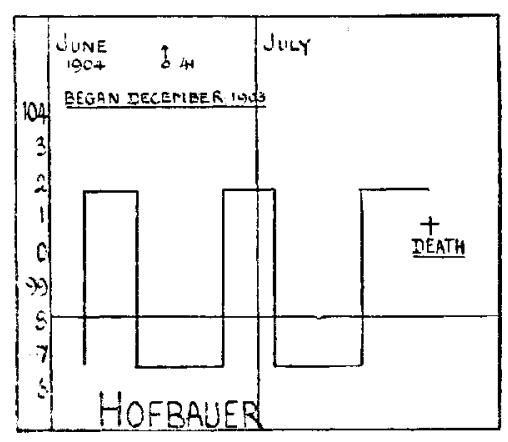

FIG. 20 


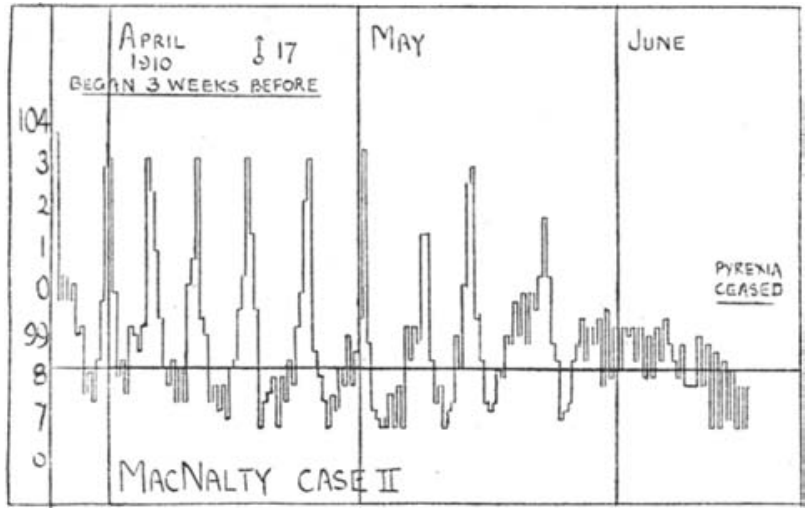

Fia. 21

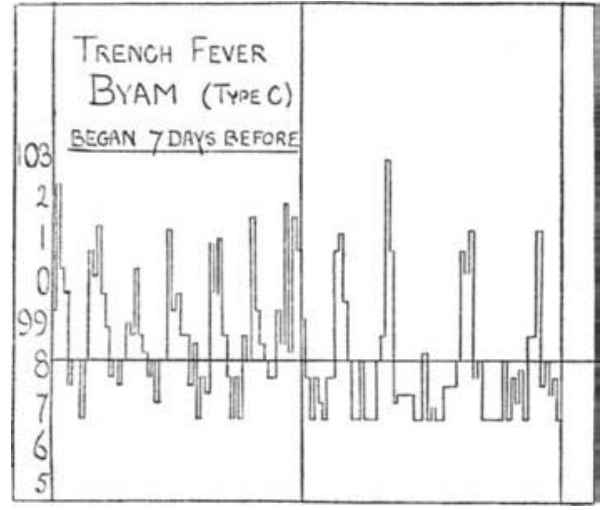

FIG. 22

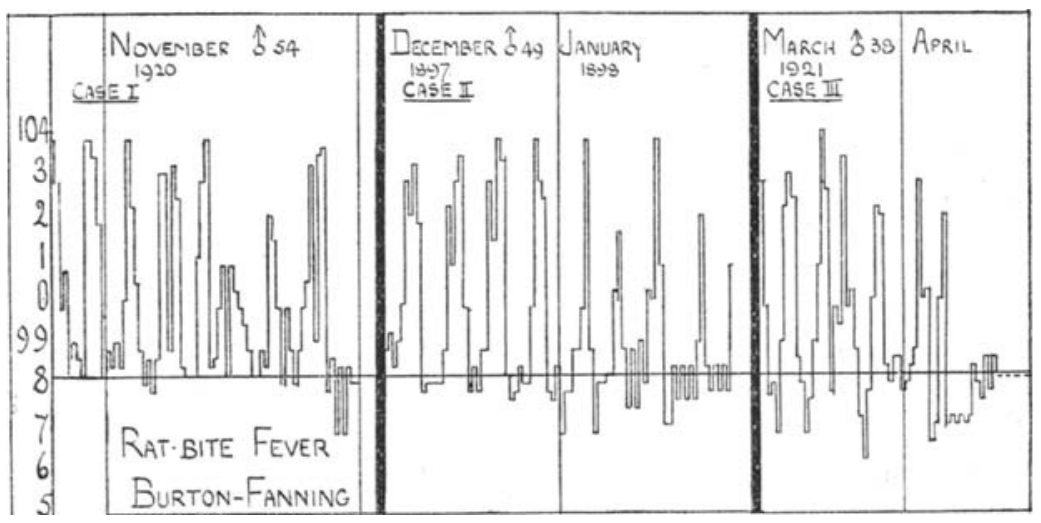

FiG. 23

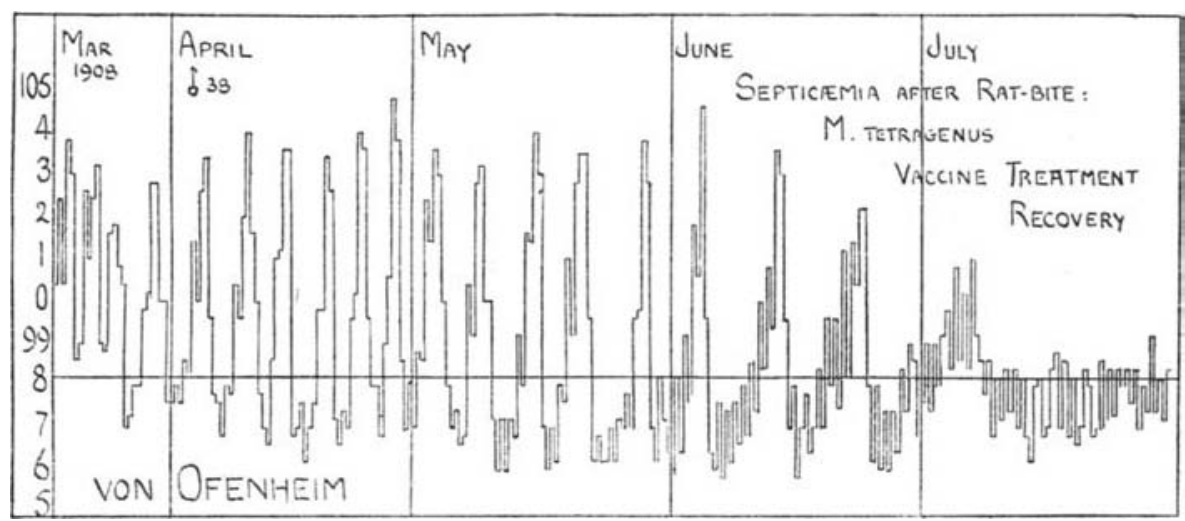

Fig. 24 


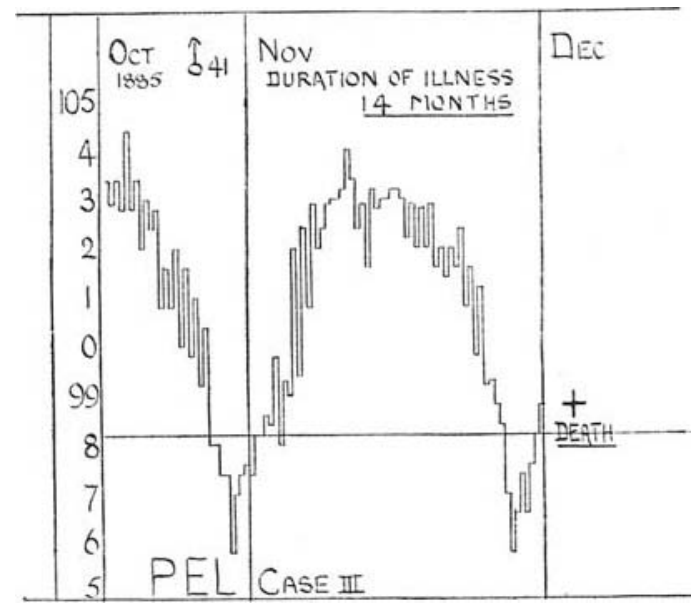

Fia. 25

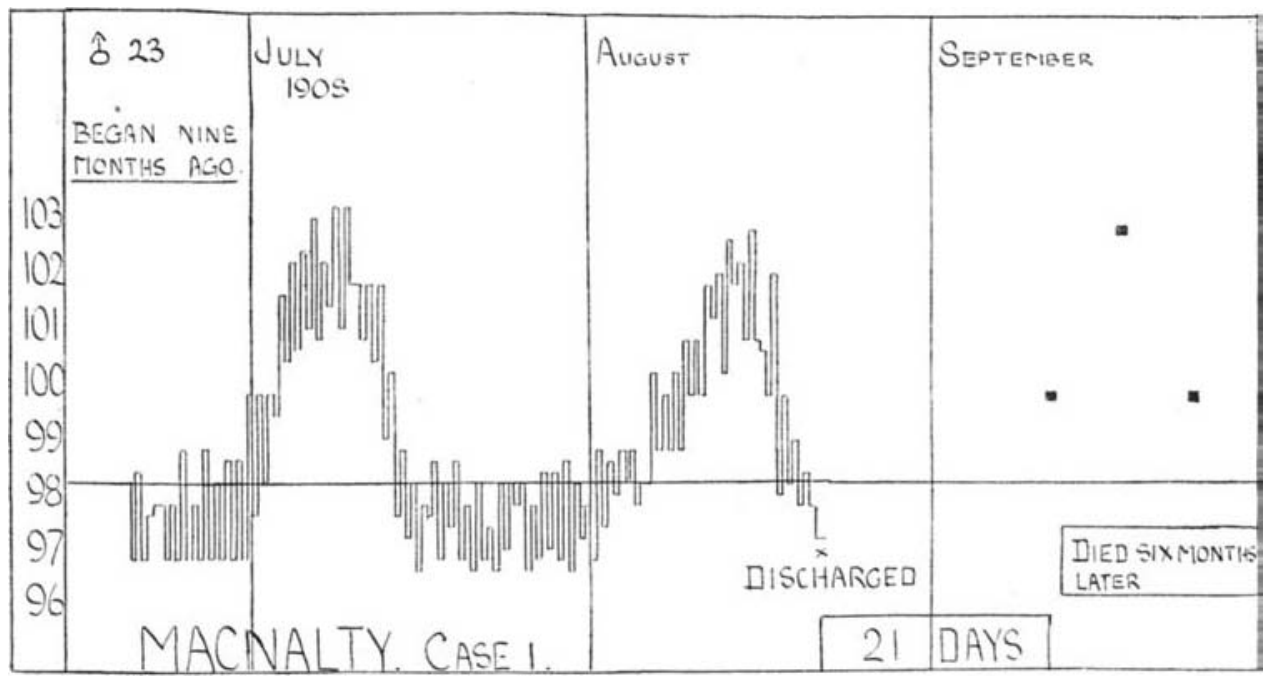

FrG. 26 